\title{
O CUIDADO À EQUIPE MULTIDISCIPLINAR
}

\author{
THE CARE FOR THE MULTIDISCIPLINARY TEAM
}

Maria Auxiliadora Borges dos Santos

Psicanalista. Membro Associado da Sociedade Brasileira de Psicanálise de São Paulo e Membro Associado da Sociedade Brasileira de Psicanálise de Ribeirão Preto

CorRESPONDÊNCIA: Rua Garibaldi, 2759. CEP 14025 190. Ribeirão Preto-SP. E-mail:mauxborges@netsite.com.br

Borges dos Santos MA. O cuidado à equipe multidisciplinar. Medicina (Ribeirão Preto) 2006; 39 (3): 425-32.

RESUMO: Dentro da conceituação sobre o que constitui um trabalho suficientemente bom, que satisfaça as necessidades clínicas que emanam do paciente com transtorno alimentar (TA), uma reflexão nascente se impõe como parte dessas exigências: o cuidado à equipe multidisciplinar, não tendo este, caráter dispensável, mas absolutamente indispensável como instrumental que visa alicerçar melhor, os profissionais envolvidos nesta tarefa. A autora, psicanalista, sonda o relacionamento medico - paciente atual, inserido na cultura do vazio, onde ambos correm risco de se encontrarem num lugar esvaziado de "significados", envolvidos na árida função de contar calorias e da mensuração corporal. Tomando como exemplo um caso de obesidade mórbida a analista reflete as tensões vividas pelo médico no contato com os pacientes, e o risco de "burn-out", um tipo de sofrimento mental grave que pode acometer o profissional nestas situações. Propõe algumas soluções para este problema, que visam a ampliação do espaço mental do médico, necessário ao abrigo do paciente que lhe pede socorro.

Descritores: Transtornos da Alimentação. Equipe Multidiscplinar. Supervisão de Grupo.

Seria o cuidado à Equipe Multidisciplinar (E.M.), necessidade premente face às demandas do paciente com transtorno alimentar, ou poder-se-ia conceber este cuidado à EM, um "preciosismo", no sentido do dispensável?

Afinal, os profissionais componentes desta Equipe, não raro são especialistas em suas áreas: graduando e pós-graduando, que às vezes emergem exauridos da lida com tais pacientes. O que acontece para que tal ocorra? Porque é insuficiente a prescrição cuidadosa de uma dieta balanceada e a orientação de condutas alimentares adequadas? Porque as prescrições medicamentosas não se mostram suficientes ou então, por que os componentes de toda a Equipe passam num determinado momento a se desentenderem? As "soluções" cirúrgicas se multiplicam muitas vezes de forma antiética, e as dietas da moda são procuradas de maneira compulsiva pela população, deixando os médicos em seus consultórios vazios, sentindo-se impotentes frente às "soluções miraculosas" e charlatanescas.

Caso fosse o problema do Transtorno alimentar (TA), pertinente apenas à área intelectual e cognitiva, esses efeitos citados acima não existiriam. Bastaria o médico prescrever uma dieta balanceada, e toda a população estaria com este problema resolvido.

Como na realidade observada, não é isso o que acontece, lancemos um olhar mais acurado para alguns pontos desta situação tão ampla de ser compreendida.

Inicio estas conjecturas lançando um olhar sobre o relacionamento médico-paciente (RMP). 


\section{1- O RELACIONAMENTO MÉDICO PACI- ENTE (RMP)}

Queremos denominar aqui médico, como todo o profissional que cuidará diretamente do paciente, portador de TA. Sabemos, de longa data, que a qualidade da RMP, é determinante para o sucesso ou insucesso de qualquer tratamento proposto, não somente na área estudada. Esse conhecimento advém do fato de que o ser humano aprende algo, de forma duradoura e significativa, apenas dentro de uma relação humana amorosa. Mas, o que se pode chamar de relação humana amorosa? Ora, muitas vezes as pessoas confundem relação amorosa com relação erótica, acreditando ter que seduzir o paciente com simpatia excessiva, quando o que se faz necessário é a empatia do profissional sobre o funcionamento do paciente; é a capacidade de "conter" o paciente em seus aspectos mais fragilizados e doentios e ajudá-lo a se modificar.

Freqüientemente, o paciente chega ao médico, repleto de angústia e sintomas, para os quais não tem descrições. A situação inicial não é clara nem para o médico, nem para o paciente, que se sente neste período, no mais profundo caos e escuridão, por não conseguir colocar em palavras, as experiências repletas de sentimentos penosos que vem vivendo. Este, seria o "conteúdo" (de acordo com W.R. Bion), projetado pelo paciente, para dentro do médico agora devendo ser o "continente" (de acordo com W.R. Bion) acolhedor para o caos do paciente ${ }^{1,2}$.

O médico, conhecedor deste mecanismo, desenvolverá compreensão ao receber o paciente, pois saberá interpretar as suas agonias, como muito intensas, as quais necessitam encontrar, no médico, a "continência" necessária para conhecer seu estado de pavor e acolhê-lo; e também se sentir equilibrado para continuar ajudando o paciente por um longo período.

A este processo, de "colocar" o que se sente para dentro do médico, aquém e além das palavras, Melanie Klein descreve em 1946 como "Identificação projetiva" e que pode, segundo W.R. Bion (1962), ser normal ou anormal. Nos processos "normais" de identificação projetiva, o paciente coloca, por exemplo, o seu medo ou outra emoção, dentro do médico, certo que o médico "intuirá" sua emoção, e conversará com ele sobre seus sentimentos e fantasias. Neste caso, o paciente sente ter o vínculo com o médico, realizado e fortalecido ${ }^{3}$.

No caso de identificação projetiva anormal, o paciente "evacua" o seu estado mental penoso para dentro do médico, com o propósito de alcançar alívio imediato. Amiúde, com o objetivo de controlar o médico, que, se não conhecer este mecanismo, não poderá ser um bom continente para os conteúdos aflitivos de seu paciente, tendendo a fazer ou "obedecer" ao que o paciente quer que ele faça. Isso será melhor descrito adiante.

\section{2- O TRANSTORNO ALIMENTAR COMO SINTOMA E NÃO COMO DOENÇA}

A contemporaneidade que vivemos caracteriza-se pela destruição do "tempo e do espaço", necessários para o homem constituir a sua subjetividade. É no tempo e no espaço mental materno, desde intraútero, que o ser em formação irá desenvolver sua capacidade de pensamento e seus instrumentais para lidar com o mundo externo e seus avatares.

Vivemos numa sociedade de consumo, onde a imagem é valorizada, em detrimento dos valores profundos do ser humano, criando-se um homem superficial e narcísico, cujo instrumento de abordagem é a sedução e o jogo do poder.

A realidade é banalizada, a violência das relações é legitimada e a insignificância dos sentimentos determina a busca pelas relações concretas e materiais, onde o Ter é sinônimo da independência almejada. A vida passa a ter cunho de um grande espetáculo de falsas representações.

É neste cenário, que observamos a emergência de novas doenças mentais, onde o ponto de convergência é o VAZIO.

O bebê, quando acolhido na "mente da mãe", conta com um "espaço mental" que o abriga e o acolhe, e propicia o pensamento do ser e todo o seu desenvolvimento ulterior. Quando este bebê, gerado num "ventre mental" extemporâneo, hedonista e narcísico, não encontra o acolhimento necessário, surge no bebê, a sensação de ter sido gerado num vazio sem calor e sem resposta, informe e sem sustentação. Neste cenário primeiro, o desejo pelo humano aliena-se, e dá primeiro lugar para à busca de satisfação das necessidades orgânicas apenas. Um ser humano, pleno de VAZIO nasceu. Autista, associável, desejando viver livremente e sem repressões. A mente não-nascida dá lugar ao funcionamento do cérebro, como se fosse esse ser, apenas um ente fisiológico, que vai procurar viver a vida no arco-reflexo e resolver seus problemas na imediatez, o que culmina em "soluções" banais e até criminosas para se atingir os objetivos dese- 
jados. Todo o pensar e a condição reflexiva do ser é tida como preciosismos ultrapassados, embora esse mesmo ser, busque às vezes através de equívocos encenados, viver experiências verdadeiras e nutridoras da mente vazia e "esfaimada" pela verdade.

Dessa forma, para lidar com esta condição esvaziada da mente do paciente, a mente do médico é requerida de forma diferente, e a sua função passa a ser mais complexa, uma vez que terá de se preparar para este novo paciente que lhe exige outra postura, não somente organicista, pois que se assim for, ambos, cairiam no VAZIO informe.

Desta forma, bulimia, anorexia e obesidade mórbida constituem neste cenário espetacular, linguagens desesperadas, constituintes em sintomas que designam o desamparo do ser contemporâneo diante de si próprio e do mundo, no aguardo de encontrar um médico que possa transformar em palavras, a gramática especial do psicossomático.

\section{3- O FUNCIONAMENTO MENTAL DO PACI- ENTE COM TA}

O paciente busca a equipe médica numa condição de extrema fragilidade mental, que observada mais cuidadosamente, oculta um estado de "terror sem nome", ante o qual, o paciente se defende, através de defesas muito primitivas, descritas por Melanie Klein, psicanalista européia, em $1946^{3}$.

\section{1- Cisão}

O paciente chega com a mente dividida em bom e mau; desta forma, sem condição interna de perceber os bons aspectos lado a lado com os aspectos frustrantes; julgará a tudo e a todos de forma estanque. Ex: ou o médico é lindo, bom e eficiente quando "agrada" o paciente ou é mau e tenebroso, ao frustrálo. Há uma intolerância acentuada às frustrações nestes pacientes.

\section{2- Idealização}

É típico encontrar uma idealização (ampliação dos aspectos positivos) dos bons aspectos. Ex.: o bom médico, é visto como perfeito. Mas, para que isto seja possível é necessário que uma outra defesa entre em funcionamento: a negação.

\section{3- Negação}

Corresponde à fantasia de aniquilar aqueles aspectos que são frustrantes e intoleráveis para a mente. Dessa forma, a idealização aumenta espetacularmente os bons aspectos. Ex.: o paciente nega o aspecto frustrante do médico e do trabalho desempenhado, e assim, "constrói” um médico perfeito, via idealização.

\section{4- identificação projetiva}

(Vide item 1). O paciente com TA usa maciçamente a identificação projetiva anormal, quando "evacua" seu desamparo dentro do médico, para obtenção de alívio imediato.

\section{5- Triunfo}

Caso o paciente não se sinta "acolhido" nos seus conteúdos mais desesperadores como por exemplo, sentir que não pode contar com o médico de forma onipotente, passará a desprezá-lo e tentará negar o vínculo de dependência com o mesmo, mostrando-se "independente" e triunfante sobre os esforços médicos. Essa defesa é vinculada à onipotência.

Essas defesas todas, conferem ao paciente um caráter onipotente e frágil ao mesmo tempo, e não raro, exibindo comportamento auto e hetero-agressivo, dentro de um vínculo extremamente frágil com o médico, pouco tolerante às frustrações inerentes ao tratamento proposto.

\section{4- EXEMPLO CLÍNICO}

Trarei à luz um caso clínico de um adolescente que acompanho há mais ou menos 10 meses e que revela fortes ansiedades intra-psíquicas.

Antes gostaria de pensar algo sobre a prevalência dos transtornos alimentares na Adolescência.

Segundo Kanciper (2005)*, "a adolescência é a etapa de resignificação por excelência. Aquilo que foi silenciado na infância, se manifestará aos gritos na adolescência. A patologia se instala quando não há confrontação, dando lugar ao sintoma. O nosso trabalho é portanto, trocar o sintoma pelo confronto". Mas, para que tal seja possível, é necessário ampliar as condições de continência do profissional e da família. É preciso haver espaço mental para abrigar o confronto necessário.

\footnotetext{
* Comunicação oral de Congresso: Kanciper L. Adolescência: el fin de la ingenuidad. Curso integrante do 44ํㅡㄹ Congresso da International Psychoanalytical Association (I.P.A.), sediado no Rio de Janeiro, Julho 2005.
} 
Mário, adolescente com obesidade mórbida, 15 anos, foi-me encaminhado para análise, há \pm 10 meses; é um jovem alegre, inteligente, com traços de megalomania. Tudo para Mário tem que "jorrar aos borbotões". O pouco é desprezado e a espera é aterrorizante para ele.

Mário: "Enfim, comprei meu "Ipod". Tenho 2500 músicas na memória”. Mário gostaria de ter tudo..., de não ter que renunciar a nada... Esperar, ter que renunciar, o preenche de terror. Terror tão grande, que não tem adjetivo. "Terror sem nome".

$\mathrm{O}$ inconsciente manifesta-se nas várias linguagens: corporal, verbal, nas atuações. O psicanalista, cuja tarefa é traduzir essas várias linguagens, e desvendar o inconsciente para o paciente, guia-se pelo "outro significado" escondido no nome do aparelho chamado "Ipod" I-pod, I pode 2500 músicas, I pode tudo, Eu posso tudo. Vou mostrando o seu inconsciente, suas agonias nascentes frente as limitações inevitáveis, e Mário vai se fortalecendo internamente para enfrentar as restrições alimentares, até porque eu já estou instalada em sua memória. Passa a perder peso, mesma sob orientação nutricional incorreta, sinal de sua dificuldade em procurar a seguir uma orientação séria, para toda a sua vida, o que seria mais difícil para este momento de sua vida. Tolera neste momento, uma "dieta passageira", que o leva a perder algum peso, para viajar aos E.U.A.

Neste momento, começa a sentir dificuldades para seguir em análise; as resistências ao trabalho aparecem e Mário, com medo de "perder o seu lugar" dentro de mim nas férias, passa a acenar um adeus à análise.

Isso fica claro no desenho que faz na sessão que antecede as férias. Afinal, ao mesmo tempo que internamente leva a analista perceber que "Eu não posso tudo...", o aterroriza. (Figura 1).

Virando este desenho, eu pude ver o magro; Mário completa o desenho, quando eu the mostrei o "outro". E aí, o desenho passou a conter o Magro no Gordo: (Figura 2).

Ao que Mário diz, visivelmente impactado diante do desenho:

"Tenho um magro dentro de mim, olha só!" Mas ambos, Gordo e Magro, dizem-me Adeus. Se Gordo, se sente o "maioral" não precisando de Análise. Se Magro, rejeita toda a ajuda, colocando-se como magro-anoréxico que enjeita a "comida-verdade" da análise. Assim, Mário me faz sentir "Impotente" diante de sua impotência, via Identificação Projetiva. Mas,

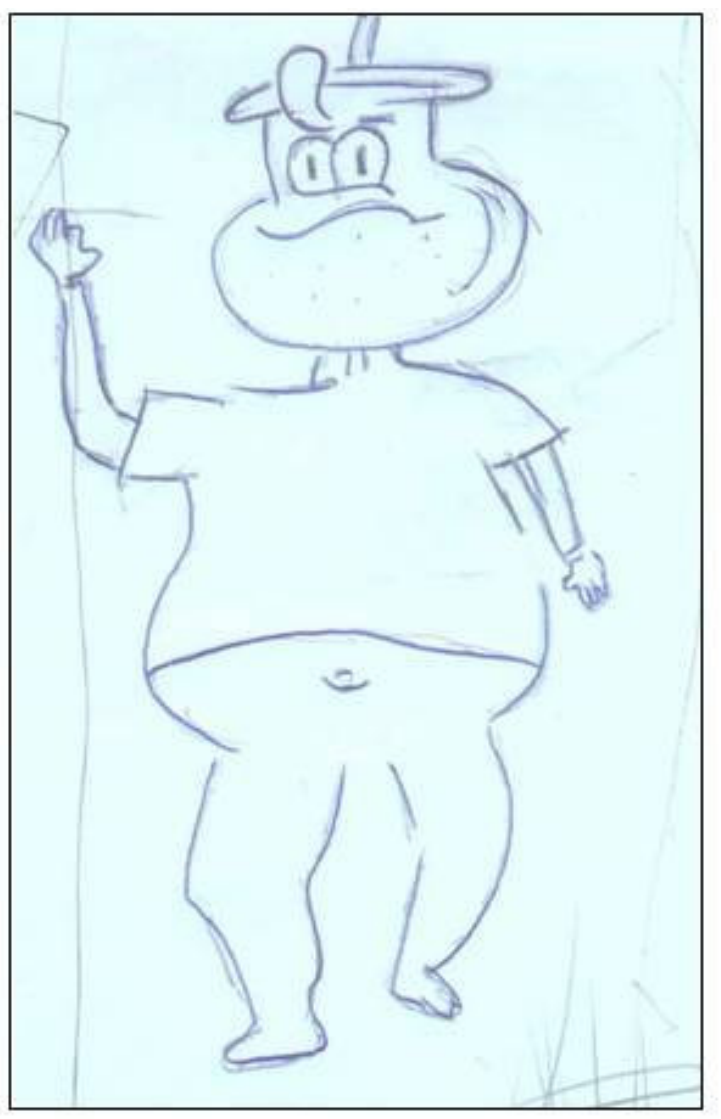

Figura 1: "O gordo" . Obs. Virar a folha para ver o magro na cabeça do gordo.:

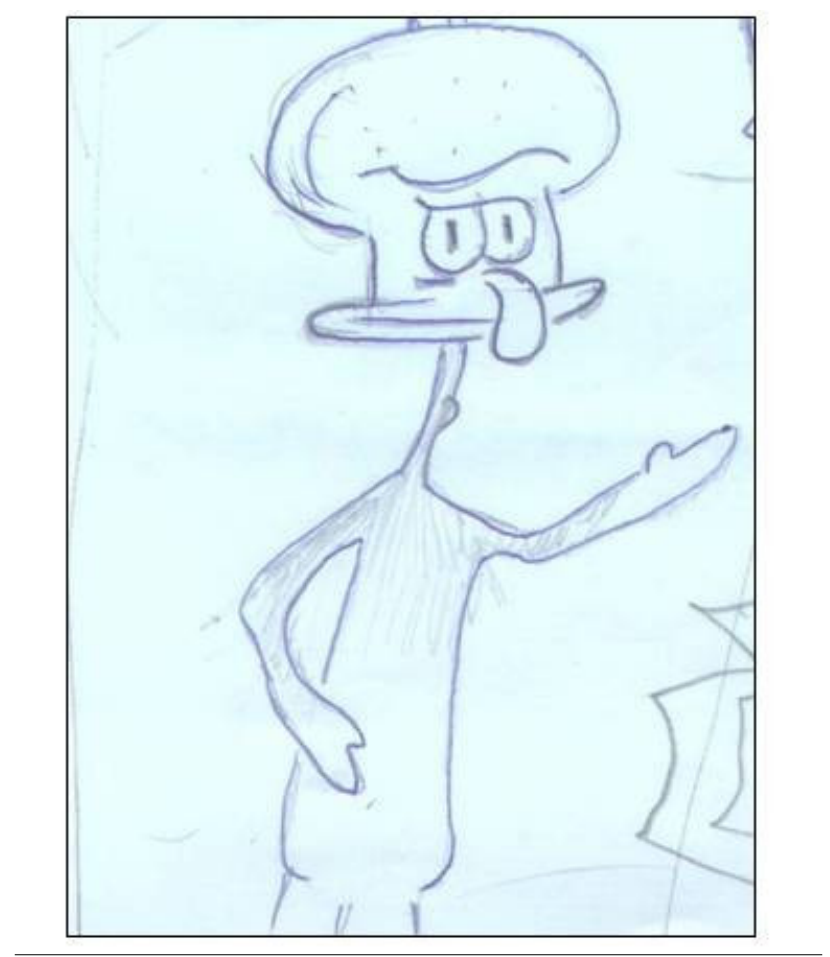

Figura 2: O magro" 
lançando mão de "Continência", vou conversando com o paciente sobre "o terror sem nome" que vive diante de sua impotência - e Mário vai compreendendo, vagarosamente, a sua situação interna, o que estimula-o a continuar. $\mathrm{O}$ sintoma-obesidade vem encontrando canal de expressão no confronto vivido pela dupla.

Assim, este tipo de paciente, está sempre prestes a nos desafiar, e nos deixa, tão logo percebem que não temos nenhum milagre a lhes oferecer. Somente com o conhecimento da mente destes paciente é que podemos construir um caminho possível de ser trilhado pela dupla, que não raro é longo e difícil. Na Figura 3 temos o desenho completo.

\section{5- TENSÕES VIVIDAS PELO MÉDICO NA RMP}

São quatro, no mínimo, as fontes de tensões experienciadas pelo médico, no atendimento com esses pacientes.

\section{1- Vividas diretamente no contato clínico com o paciente}

Sendo estes pacientes, portadores de um nível de angústia muito elevado, e que como já dissemos, estão em busca de "continência" que reverta o sintoma em confronto, ao encontrar o médico, "despejará"

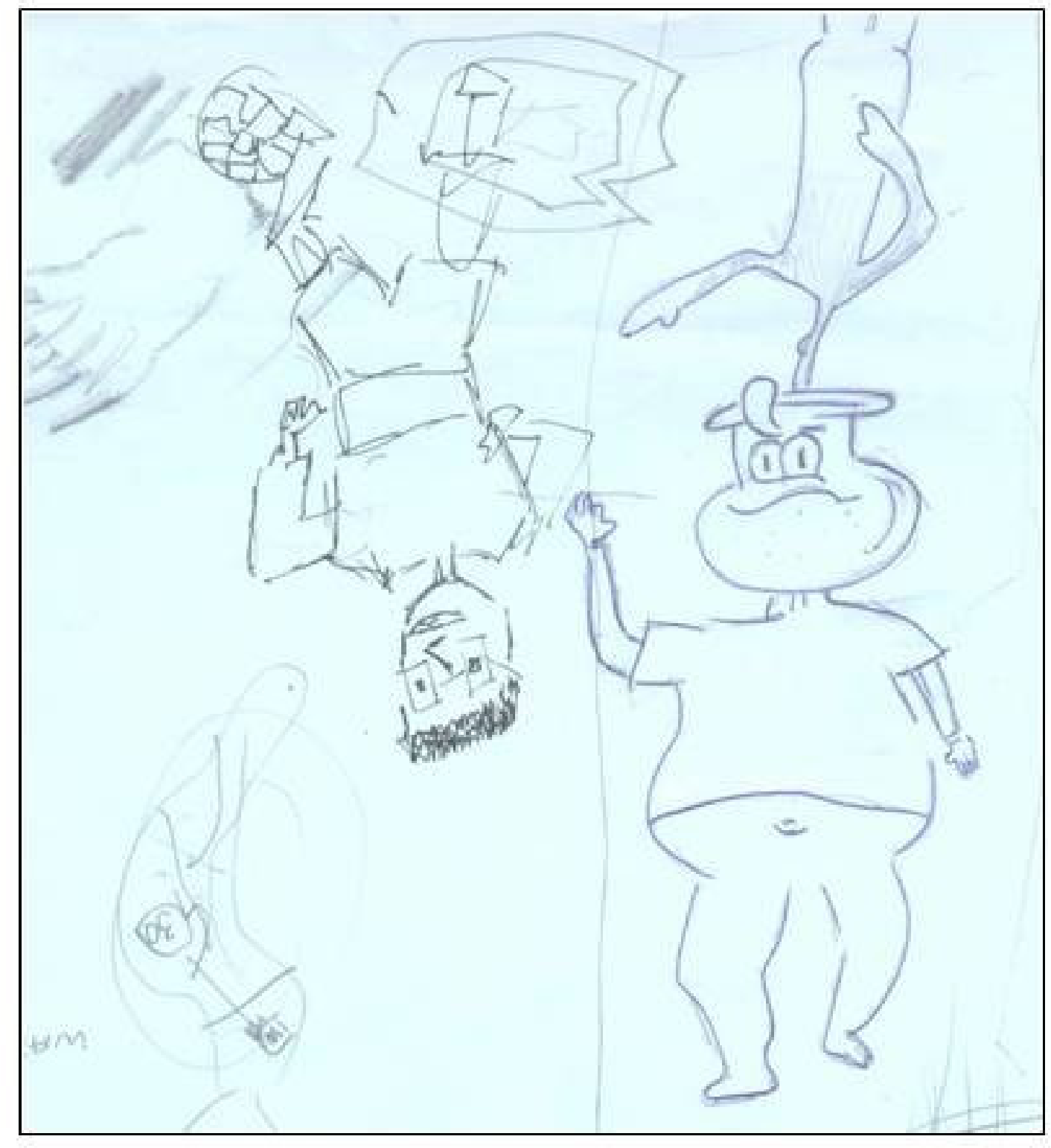

Figura 3: "O magro e o gordo" 
toda a agonia contida as vezes por toda a vida, dentro do profissional, na situação clínica, ou até mesmo, fora do "setting" de atendimento, sob forma de atuações com o propósito de aliviarem-se do excedente de angústia. São pacientes que "sugam" o profissional.

\section{2- Vividas no contato com a família}

Temos aqui, as famílias muito desestruturadas do ponto de vista mental, que "construíram" um indivíduo-sintoma, sobre o qual todo o funcionamento da família está erigido. Sendo assim, intervir neste "equilíbrio precário" pode resultar em mudanças vividas como catastróficas por toda a família, que por sua vez, se endereçará toda para o médico.

\section{3- Tensões oriundas de seus próprios confli- tos privados}

O médico é alguém como todo o ser humano, que tem sua historicidade e gramática emocional própria. Alguém que também se debate com seus conflitos pessoais, assentados nas mais diversas faces da vida.

O paciente não está se consultando com um Semi-Deus, um Santo, ou um Robô. Mas com um serhumano portador de fragilidades e vulnerabilidades como qualquer outro ser mortal, que enfrenta suas tristezas, traumas antigos e recentes, perdas dolorosas, violências oriundas da mundanidade, enfim, o médico também é um ser que sofre a vida como o paciente. A diferença entre ambos é que se espera que o médico porte instrumental de conhecimentos, acerca do paciente e acerca de si mesmo, que faça frente à demanda do paciente.

\section{4- Tensões vividas dentro da equipe}

A Equipe Multidisciplinar que atende este tipo de pacientes é componente de seres humanos, pleno de conhecimento técnico obtidos em suas áreas de especialização, mas que sofre todas essas tensões, descritas acima, e que são tocados em suas áreas de vulnerabilidade a todo o momento. Tensões que vem do paciente, da família, dentro do médico, e também ao ter que conviver com seus colegas, oriundos de outras áreas de conhecimento e falando outras linguagens; o que muitas vezes, resulta em áreas de confronto muito delicadas, e para as quais, convergem todos os conteúdos de agonia.

\section{6- EFEITOS DAS TENSÕES DO MÉDICO}

Não raro, o paciente com transtorno alimentar, pode funcionar, de maneira a atingir áreas de vulnerabilidade do médico, dado a gravidade do estado mental com que o paciente aborda o médico.

Dessa forma, o médico pode reagir ao paciente com:

\section{1- Contratransferência intensa}

Queremos denominar como contratransferência, o conjunto de sentimentos e emoções que o médico vive, despertado na relação com o seu paciente. $\mathrm{O}$ médico pode se sentir tomado por fortes emoções ou sentimentos variados, e na maioria das vezes, não "sabe" o que está se passando e nem o nome das emoções vividas. Por exemplo, pode sentir ódio do paciente, se este não "segue" as orientações recomendadas, ao invés de manter espírito observador.

\section{2- Sofrimento narcisista}

O médico pode se achar "vítima" do paciente, ou então, pode achar que não "merece" passar por essa experiência, ou ter vontade de parar de tratar o paciente, por "sofrer" algo que acha despropositado para um médico.

\section{3- Sujeição masoquista}

O paciente com transtorno alimentar pode, em decorrência de alguma piora, culpar o médico pelo seu retrocesso ao invés de se responsabilizar por isso, e o médico pode reagir se identificando com a culpa projetada sobre ele pelo paciente. Pode passar com isso a "se sujeitar ao que o paciente pensa ou deseja".

\section{4- Sentimento de fracasso ante a ausência de progresso do paciente}

O paciente, não se responsabilizando pela sua parcela no tratamento, pode por "identificação projetiva" (como descrito no item 1), colocar a sua frustração e sentimento de fracasso dentro do médico, que, poderá ser identificar com este sentimento do paciente e se achar incompetente para prosseguir no tratamento. Diante desta situação, o médico deve se questionar se de fato a ausência de progresso se deve à falha sua, ou se constitui algum ataque do paciente à si e ao tratamento proposto pelo médico.

\section{5- Auto-idealização}

Constitui numa crença delirante de que "eumédico-sou sempre o correto", e o seu corolário: "este 
paciente - é muito doente mesmo; e não conseguiria nada com ninguém". Essa defesa do médico é impeditiva de uma atitude aberta à investigação contínua sobre si, sobre o paciente, e sobre como a dupla está funcionando, de modo a alcançar a meta proposta.

\section{6- Sedução do paciente}

O médico, para fugir de uma postura de "pensa-dor", diante da situação difícil em que o paciente se encontra, pode tentar "seduzir" o paciente com "agrados" e "simpatias" dispensáveis. O médico deve ocupar, lugar de "continência" frente às dores mentais do paciente e não de sedutor. Poderá com a sedução perverter o "setting" de trabalho e causar algum traumatismo no paciente que, perdendo a confiança no médico, poderá não procurar mais nenhum tipo de ajuda.

Por outro lado, esta situação poderá ser induzida pelo próprio paciente, que virá para "namorar" o médico, tentando "distraí-lo" de sua função de médico.

\section{7- Vínculo conivente entre M-P}

Temos aqui, a perversão da indulgência, onde "tudo é permitido"; o médico passa a ter dificuldades de frustrar o paciente; tenderá a protegê-lo, ficará com o "dó" do esforço requerido, ou excessivamente indulgente. Existem várias formas de conivências entre M-P e o médico deve ficar sempre atento se não está incorrendo neste risco.

\section{8- Desenvolvimento de sintomas}

Que pode ser o mesmo sintoma que o paciente apresenta, ou, o oposto. Ex., se a paciente é anoréxica, o médico tenderá, a ficar anoréxico ou o oposto, obeso. Várias razões, todas de origem fantasiosa, se observa neste quadro. Por exemplo, o médico poderá mostrar que "comer é bom" à anoréxica, ganhando peso e evidenciando ao paciente, que "comer é algo bom"... Ou, o contrário, se se tratar de paciente obeso, o médico poderá perder peso para "ajudar" o paciente.

\section{7- A SÍNDROME DE "BURN-OUT"}

De acordo com Ricardo Bernardi (2005)*, as dificuldades da RMP podem se agravar e vir a ser permeada por agonias impensáveis e tomar uma forma específica de sofrimento mental que se manifestará na síndrome de "burn-out".
"Burn-Out" significa "em brasa", relação "abrasada" e caracteriza-se por:

1- esgotamento emocional do médico

2- depressão, uso de psicotrópicos e álcool

3- relacionamento MP impessoal, frieza, distanciamento, atuações no sentido de controlar o paciente, intimidá-lo com as conseqüências, ou ter atitudes autoritárias

4- Sentimento de falta de realização pessoal, podendo se sentir fracassado perante o paciente

5- Perda de criatividade, indiferença ou perda de empatia

6- Desilusão

De acordo com nossas observações, o "burnout" se relaciona a soluções inadequadas, às vezes doentias e por fim, o encaminhamento do paciente à cirurgias bariátricas ou à medicalização desnecessária, sendo premente, revisar as indicações cirúrgicas ou medicamentosas, pois estas podem existir em função do estado mental do médico, e não da real necessidade do paciente.

Um médico vivendo em "burn-out", está altamente predisposto à dissociações e acting-outs, frente às identificações projetivas do paciente, e para as quais, não desenvolveu a necessária continência propiciadora de estado de observação do paciente.

\section{8- UMA EXPERIÊNCIA DE GRUPO DE ES- TUDO}

No entrecruzamento destas facetas todas que analisamos anteriormente, nossa preocupação volta-se ao médico que, espera-se, disponha um espaço interno que contenha as agonias de seu paciente, e de instrumental, não apenas o que recebeu nos vários níveis de graduação, mas que tenha equipamento psíquico que faça frente a tão dispendiosa tarefa. O paciente necessita contar com um médico apto, emocional e intelectualmente. Dessa forma, acreditamos ser indispensável a busca ativa de colaboração que objetive a ampliação da "continência" interna, para estar apto a acolher os "conteúdos" do paciente, sua família, e equipe de trabalho, e assim, dar guarida ao ser humano que o procura, por longo caminho, sem ele próprio adoecer.

Existem, neste caminho de colaboração, três medidas úteis e de enorme valor, que tenho testemunhado. 1- psicoterapia ou análise do profissional, 2- supervisão do trabalho clínico com seus pares,

* Comunicação oral de Congresso: Bernardi R. Contratransferência, trauma e vulnerabilidade do analista. Curso ministrado no 44ํㅜ Congresso da International Psychoanalytical Association (I.P.A.) sediado no Rio de Janeiro, Julho 2005. 
3- participação em grupos de estudos, voltado não só para a compreensão do mundo mental dos paciente, mas também como "espaço" de troca de experiências entre os profissionais.

Quero deter-me um pouco sobre o último item, ou seja, sobre os Grupos de Estudos.

Mais particularmente, tenho desenvolvido um trabalho em grupo de estudos de psicanálise, visando mais precisamente o profissional que atende o paciente com TA. Temos, juntamente com nutricionistas, psicólogos, psiquiatras e nutrólogos, a três anos, os conceitos de Sigmund Freud, Melanie Klein, W.R. Bion, Donald Winnicott e outros, o que tem sido de grande valia na instrumentação necessária do profissional desta área.

Quando o médico, adquire, através deste instrumental, visão profunda sobre o paciente, amplia-se nele, a continência interna para conviver e pensar com o paciente, mantendo-se lúcido nesta tarefa, que não raro é árdua e longa. Temos incentivado os profissionais componentes do Grupo, a procurarem por suas análises ou psicoterapias, onde poderão elaborar profundamente suas dificuldades e facilidades e também à supervisão técnica com seus pares. Dessa forma, tenho observado a remissão de alguns quadros de "burn-out", com o qual o médico chega ao grupo, e o desenvolvimento da capacidade para o pensamento em grupo.
O clima de troca e de confiabilidade interna do grupo, tem propiciado o "Espaço" necessário para que o médico desenvolva a sua função de forma lúcida.

\section{9- REFLEXÕES FINAIS}

Somos seres necessitados de acolhimento dentro de um outro ser. Isso significa que somos sozinhos e dependentes em nossa condição humana. E portanto, para que possamos desenvolver, primeiro precisamos aceitar nos envolver com o outro, portador de um espaço mental que nos acolha, para o necessário "desenvolvimento" ulterior.

Toda a nossa questão é: como ampliar este espaço, necessário ao abrigo do paciente que nos procura?

Como já mencionamos, o transtorno mental é sintoma de doença mental crônica, sem solução simples e que abala, além do paciente, a família e não raro, a equipe toda de trabalho.

Se é o médico, a "testa de ferro" do problema, e considerando-se às áreas de vulnerabilidade deste, a pretensa classificação que envolve o cuidado da equipe, como sendo "preciosismo" é perigosa e superficial, principalmente se considerarmos os sérios riscos envolvidos na tarefa, sobretudo aqueles envolvidos à Ética do trabalho e Saúde Mental do médico.

Borges dos Santos MA.The care for the multidisciplinary team. Medicina (Ribeirão Preto) 2006; 39 (3): 425-32.

Abstract: Within the conceptual approach to what represents a sufficiently good intervention that will satisfy the clinical needs of patients with eating disorders (ED), an incipient reflection becomes part of these requirements: the care for the multidisciplinary team. This is not of a dispensable nature, but is absolutely indispensable as an instrument aiming at a better foundation for the professionals involved in this task. The author, a psychoanalyst, examines the current doctor-patient relationship, which is inserted in the culture of vacuum, where both are at risk to be in a place emptied of "meanings" and to be involved in the arid function of counting calories and performing body measurements. Taking as an example a case of morbid obesity, the analyst reflects on the tensions experienced by the doctor in his contact with the patients and on the risk of burn-out, a type of severe mental suffering that may affect the professional in these situations. The author proposes some solutions for this problem aiming at the expansion of the mental space of the doctor, which is necessary to shelter the patient who asks for help.

Keywords: Eating Disorders. Multidisciplinary Team. Group Supervision.

\section{REFERÊNCIAS}

1 - Bion WR. Atenção e interpretação. Rio de Janeiro: Editora Imago; 1970.

2 - Bion WR. In: Hinshelwood, RD. Dicionario do pensamento Kleiniano. trad. de José Octávio de Aguiar Abreu. São Paulo: Artes Médicas; 1992. p. 198.
3 - Klein M. Notas sobre alguns mecanismos esquizóides. In: Klein M. Progressos da psicanálise. $3^{\underline{a}}$ ed. Rio de Janeiro: Zahar; 1982. p. 313-43.

4 - Lisondo ABD. Na cultura do vazio: patologias do vazio. Rev Bras Psicanal 2004; 38 (2): 335-58. 